Research Article

\title{
Cloning, Expression, Purification, and Characterization of Glutaredoxin from Antarctic Sea-Ice Bacterium Pseudoalteromonas sp. AN178
}

\author{
Quanfu Wang, ${ }^{1}$ Yanhua Hou, ${ }^{1}$ Yonglei Shi, ${ }^{1}$ Xiao Han,, ${ }^{1}$ Qian Chen, ${ }^{1}$ \\ Zhiguo Hu, ${ }^{1}$ Yuanping Liu, ${ }^{2}$ and YuJin $\mathrm{Li}^{3}$ \\ ${ }^{1}$ School of Marine and Technology, Harbin Institute of Technology, Weihai 264209, China \\ ${ }^{2}$ Shandong Provincial Engineering Technology Research Center of Marine Health Food (Taixiang Group), Rongcheng 264300, China \\ ${ }^{3}$ Shandong Provincial Key Laboratory of Processing Technology of Frozen Prepared Food (Taixiang Group), Rongcheng 264300, China \\ Correspondence should be addressed to Yanhua Hou; houyanhua2006@163.com and YuJin Li; r.lyj@163.com
}

Received 28 April 2014; Revised 22 June 2014; Accepted 24 June 2014; Published 7 July 2014

Academic Editor: Bo Zuo

Copyright (C) 2014 Quanfu Wang et al. This is an open access article distributed under the Creative Commons Attribution License, which permits unrestricted use, distribution, and reproduction in any medium, provided the original work is properly cited.

Glutaredoxins (Grxs) are small ubiquitous redox enzymes that catalyze glutathione-dependent reactions to reduce protein disulfide. In this study, a full-length Grx gene (PsGrx) with 270 nucleotides was isolated from Antarctic sea-ice bacterium Pseudoalteromonas sp. AN178. It encoded deduced 89 amino acid residues with the molecular weight $9.8 \mathrm{kDa}$. Sequence analysis of the amino acid sequence revealed the catalytic motif CPYC. Recombinant Ps Grx (rPsGrx) stably expressed in E. coli BL21 was purified to apparent homogeneity by Ni-affinity chromatography. $\mathrm{r} P \mathrm{G}$ rx exhibited optimal activity at $30^{\circ} \mathrm{C}$ and $\mathrm{pH} 8.0$ and showed $25.5 \%$ of the activity at $0^{\circ} \mathrm{C}$. It retained $65.0 \%$ of activity after incubation at $40^{\circ} \mathrm{C}$ for $20 \mathrm{~min}$ and still exhibited $37.0 \%$ activity in $1.0 \mathrm{M} \mathrm{NaCl}$. These results indicated that $\mathrm{r} P \mathrm{~s} G \mathrm{rx}$ was a typical cold active protein with low thermostability.

\section{Introduction}

Glutaredoxins (Grxs) are ubiquitous small disulfide oxidoreductases and members of the thioredoxin (Trx) fold superfamily. They catalyze the reduction of protein disulfides and of glutathione- (GSH-) protein mixed disulfides in a coupled system with GSH, NADPH, and glutathione reductase (GR) [1]. Grxs were first discovered in E. coli as a hydrogen donor for ribonucleotide reductase and regulated protein activity by reversibly reducing disulfide bonds in their targets to achieve their role in antioxidative response [2]. Subsequently, Grxs have been isolated and identified from different organisms, including E. coli, Saccharomyces cerevisiae, Chlamydomonas reinhardtii, Synechocystis PCC 6803, Oryza sativa, Populus trichocarpa, and human Homo sapiens [3-6]. For example, in yeast 8 members of Grxs have been found, named Grxl to Grx8 in chronological order of identification $[3,5] .31$ members of Grxs in Arabidopsis, 4 members of Grxs in E. coli, and 3 Grxs members in humans were discovered and studied [7]. Grxs could participate in a variety of cellular functions, such as providing reduction of equivalents for ribonucleotide reductase, antioxidant defense, control of cellular redox state, and the redox control of transcription and signal transduction $[8,9]$. Thus Grxs from different species, or even different strains of the same species, may differ in their structural, catalytic, and functional properties.

Antarctic sea-ice is considered the unique, mostly pristine, and extreme environment. Microbes living within the sea-ice have a high degree of biochemical and physiological adaptation to low temperature, high level of dissolved oxygen, and changeable salinity conditions [10]. Several studies have shown that such extreme environments can induce excessive accumulation of reactive oxygen species (ROS), which will damage macromolecules and thus change normal signal conduction in Antarctic microbes [11, 12]. To cope with such oxidative damage and insure normal signaling events, Antarctic microbes have developed complex and precisely controlled antioxidant systems by regulating 
cellular gene expression which enables organisms to maintain proteins and other cellular components as usual. Antarctic fungi Penicillium sp. could increase activities of antioxidant enzymes such as catalase and superoxide dismutase for adaptation to the high oxygen concentration [13]. Thioredoxin and thioredoxin reductase from the Antarctic psychrophilic eubacterium Pseudoalteromonas haloplanktis were investigated through the heterologous expression of their genes and the biochemical investigation on the recombinant proteins [14]. Our recent studies have suggested that glutathione Stransferase (GST) can play a major role in a coordinated protection mechanism against low temperature in Antarctic sea-ice bacterium Pseudoalteromonas sp. [15]. Glutaredoxins, as antioxidant proteins, were known to be involved in ROS elimination and cellular oxidative-reductive balance [16]. Thus, Antarctic sea-ice microorganisms would be the new and potential sources of oxidative stress-inducible enzymes. To our knowledge, Grxs from Antarctic bacteria have been not biochemically characterized. The present work reports the molecular cloning, expression, and characterization of a novel Grx from sea-ice bacterium Pseudoalteromonas sp. AN178.

\section{Materials and Methods}

2.1. Bacteria Cultivation and Collection. Strain AN178 was identified as Pseudoalteromonas sp. based on 16S rRNA gene sequence. It was isolated from Antarctic sea-ice $\left(68^{\circ} 30^{\prime} \mathrm{E}\right.$, $65^{\circ} 00^{\prime} \mathrm{S}$ ) and was used as a source of the gene encoding Grx. Vector pET-28a (+) and E. coli BL21(DE3) were used for Grx gene cloning and expression.

Strain Pseudoalteromonas sp. AN178 was inoculated in the $2216 \mathrm{E}$ medium (peptone $0.5 \%$, yeast extract $0.1 \%, \mathrm{pH}$ 7.5 , made by natural sea water) with shaking at $120 \mathrm{rpm}$ and $8^{\circ} \mathrm{C}$. E. coli strains containing recombinant plasmids were cultured in Luria-Bertani (LB) medium containing kanamycin $(100 \mathrm{mg} / \mathrm{L})$.

2.2. DNA Manipulation and Cloning of PsGrx. The genomic DNA was isolated by using a Genomic DNA Prep Kit (Tiangen Biotech Co., Ltd., Beijing, China) according to the manufacturer's instructions. DNA purification was done using Gel DNA Purification Kit Ver.2.0 (Tiangen Biotech Co., Ltd., Beijing, China). One primer set ( $5^{\prime}$-AGGAATATRATGAGTAATGTTGTBTTAT-3', 5' ${ }^{\prime}$-ATTATAYTTAGTTAAATTTAAGCGTTBAGT-3') was designed based on the nucleotide sequences immediately upstream and downstream the known coding sequences of Grx from the genera Pseudoalteromonas. PCR reaction was carried out with the following protocol: denaturation at $94^{\circ} \mathrm{C}$ for $5 \mathrm{~min}$, followed by 30 cycles of denaturation at $95^{\circ} \mathrm{C}$ for $1 \mathrm{~min}$, annealing at $47^{\circ} \mathrm{C}$ for $1 \mathrm{~min}$, extension at $72^{\circ} \mathrm{C}$ for $1.5 \mathrm{~min}$, and a $10 \mathrm{~min}$ final extension at $72^{\circ} \mathrm{C}$.

2.3. Sequence Analysis. The open reading frame (ORF) for the PsGrx gene was determined using ORF finder (http://www.ncbi.nlm.nih.gov/gorf/) and translated into the corresponding amino acid sequence. Protein identity and amino acid sequence of PsGrx were determined by using the BLAST tool in the NCBI website and the conserved amino acids were also determined by using ClustalW program (http://www.ebi.ac.uk/Tools/clustalw2/index.html). Theoretical $p$ I values and predicted molecular masses were calculated using Prot-Param tools (http://kr.expasy.org/tools/protparam.html).

2.4. Expression and Purification of the PsGrx. The open reading frame of the DNA encoding PsGrx was amplified by PCR with the upstream primer $5^{\prime}$-CAGGGATCCATGAGTAATGTTGTTTT-3' (the BamHI site was underlined) and the downstream primer $5^{\prime}$-TATAAGCTTAGCGTTTA GTGTGGCAT-3' (the HindIII site was underlined). The PCR amplified fragment was digested with BamHI and HindIII and cloned into the expression vector pET-28a (+) to construct pETgrx. After checking the correct sequences, the recombinant vector was introduced into E. coli BL21(DE3).

Grx-fused protein was expressed in E. coli. Positive clones were screened on LB broth containing kanamycin $(100 \mathrm{mg} / \mathrm{L})$ and grown with shaking at $200 \mathrm{rpm}$ for overnight at $37^{\circ} \mathrm{C}$. IPTG (final concentration of $0.12 \mathrm{mg} / \mathrm{mL}$ ) was added to the medium at the $\mathrm{A}_{600}$ value of $0.6-0.8$. After additional cultivation at $37^{\circ} \mathrm{C}$ for $5 \mathrm{~h}$, the cells were harvested by centrifugation $\left(7500 \times \mathrm{g}\right.$ for $15 \mathrm{~min}$ at $\left.4^{\circ} \mathrm{C}\right)$ and washed with an appropriate volume of sterile water.

Recombinant PsGrx (rPsGrx) was mainly expressed as inclusion bodies. After the cells were homogenized by ultrasonic treatment, the inclusion bodies were collected by centrifugation $\left(12,000 \times \mathrm{g}\right.$ for $10 \mathrm{~min}$ at $\left.4^{\circ} \mathrm{C}\right)$. Inclusion bodies were dissolved by the binding buffer $(8 \mathrm{mM}$ Urea, $5 \mathrm{mM}$ imidazole, $500 \mathrm{mM} \mathrm{NaCl}$, and $20 \mathrm{mM}$ Tris- $\mathrm{HCl}$ ) at $5 \mathrm{~mL}$ per gram wet weight. The cell suspension was stirred for $60 \mathrm{~min}$ at room temperature, and the soluble fraction was collected by centrifugation $\left(12,000 \times \mathrm{g}\right.$ for $15 \mathrm{~min}$ at $\left.4^{\circ} \mathrm{C}\right)$. The soluble fraction was loaded to the Ni-NTA resin affinity chromatography, following the manufacturer's recommendations. The protein was eluted with an imidazole gradient $(40,100$, and $250 \mathrm{mM})$ with five column volumes at a flow rate of $1.0 \mathrm{~mL} / \mathrm{min}$. Purified protein was dialyzed by PBST containing gradient decreasing concentrations of $6,4,2$, and $0 \mathrm{M}$ urea. After a thorough dialysis the solution protein was collected and stored at $4^{\circ} \mathrm{C}$. $12.5 \%$ SDS-PAGE was applied for confirmation of the expressed product. The protein concentration was measured by Coomassie Brilliant Blue G-250 method using bovine serum albumin as the standard.

2.5. Grx Activity Assay. Grx activity was performed as described by monitoring the consumption of NADPH at $340 \mathrm{~nm}$ during the GSH-dependent reduction of $8 \mathrm{mM} \beta$ hydroxyethyl disulfide (HED) using $1 \mathrm{mM}$ GSH coupled with of 0.6 units of yeast GR (Sigma) [17]. One unit of Grx activity was defined as the amount required to oxidize $1 \mu \mathrm{M}$ of NADPH per min at $25^{\circ} \mathrm{C}$.

2.6. Biochemical Properties of $r P s G r x$. The optimal temperature for $\mathrm{rPs} \mathrm{Grx}$ in the range of $0^{\circ} \mathrm{C}$ to $60^{\circ} \mathrm{C}$ was determined in Tris- $\mathrm{HCl}(\mathrm{pH} \mathrm{7.0)}$ over $10 \mathrm{~min}$ using the standard assay 
TABLE 1: Effect of various compounds on the rPsGrx activity.

\begin{tabular}{lcc}
\hline Reagent & Concentration & Relative activity (\%) \\
\hline None & - & 100.0 \\
DTT & $10 \mathrm{mM}$ & 41.2 \\
SDS & $10 \mathrm{mM}$ & 11.3 \\
Thiourea & $10 \mathrm{mM}$ & 37.8 \\
EDTA & $10 \mathrm{mM}$ & 79.7 \\
Tween-80 & $0.2 \%$ & 53.1 \\
Triton X-100 & $0.2 \%$ & 19.0 \\
$\mathrm{H}_{2} \mathrm{O}_{2}$ & $0.2 \%$ & 9.2 \\
$\mathrm{Mg}^{2+}$ & $5 \mathrm{mM}$ & 7.0 \\
$\mathrm{Zn}^{2+}$ & $5 \mathrm{mM}$ & 5.8 \\
$\mathrm{Ca}^{2+}$ & $5 \mathrm{mM}$ & 17.2 \\
$\mathrm{Cu}^{2+}$ & $5 \mathrm{mM}$ & 15.0 \\
$\mathrm{Ni}^{2+}$ & $5 \mathrm{mM}$ & 17.0 \\
$\mathrm{Mn}^{2+}$ & $5 \mathrm{mM}$ & 39.5 \\
$\mathrm{Fe}^{2+}$ & $5 \mathrm{mM}$ & 51.5 \\
$\mathrm{Fe}^{3+}$ & $5 \mathrm{mM}$ & 51.3 \\
$\mathrm{~K}^{+}$ & $5 \mathrm{mM}$ & 26.8 \\
$\mathrm{Na}^{+}$ & $0.5 \mathrm{M}$ & 69.1 \\
$\mathrm{Na}^{+}$ & $1.0 \mathrm{M}$ & 37.0 \\
$\mathrm{Na}^{+}$ & $1.5 \mathrm{M}$ & 11.2 \\
\hline
\end{tabular}

method. The thermal stability for $\mathrm{rPsGrx}$ was measured by incubating the protein at $40^{\circ} \mathrm{C}$ and $50^{\circ} \mathrm{C}$ for $10,20,30$, and 40 min in Tris- $\mathrm{HCl}$ ( $\mathrm{pH} 7.0$ ), respectively and then directly put into an ice water bath and the residual activity was measured as described by using the standard assay. The optimal $\mathrm{pH}$ for $\mathrm{r} P s \mathrm{Grx}$ was determined at $25^{\circ} \mathrm{C}$ in the range of $\mathrm{pH} 5.0$ to 10.0 by using the following buffers: sodium acetate/acetic acid (pH 5.0), $\mathrm{NaH}_{2} \mathrm{PO}_{4} / \mathrm{Na}_{2} \mathrm{HPO}_{4}(\mathrm{pH} 5.0,6.0,7.0$, and 8.0), and Tris- $\mathrm{HCl}(\mathrm{pH} 8.0,9.0$, and 10.0). Effects of metal ions and various other agents on the Grx activity were also investigated in the standard assay, and the concentration of each reagent was indicated in Table 1 . For this, the protein was incubated with various compounds in $50 \mathrm{mM}$ Tris- $\mathrm{HCl}(\mathrm{pH} \mathrm{7.0)}$ at $20^{\circ} \mathrm{C}$ for $1 \mathrm{~h}$. Residual activity was determined under optimal protein assay conditions. Activity assayed in the absence of any additives was taken as $100 \%$. The kinetic properties for the $\mathrm{rPs} G \mathrm{rx}$ were determined at varying concentrations of HED $(0.4$ to $8 \mathrm{mM})$ with a fixed concentration of $\mathrm{GSH}$ $(1 \mathrm{mM})$. Three independent experiments were performed at each substrate concentration, and the apparent $K_{m}$ and $V_{\max }$ were calculated from Lineweaver-Burk plots.

\section{Results}

3.1. Gene Cloning and Sequence Analysis. A full-length Grx gene (Genbank accession no: KF361316) from P. sp. AN178, designated PsGrx, was composed of 270 nucleotides encoding 89 amino acid residues. The calculated molecular weight and isoelectric point of PsGrx were $9.8 \mathrm{kDa}$ and $\mathrm{pH} \mathrm{5.2,}$ respectively. In the amino acid sequence of $P s G r x$, the total number of negatively charged residues (Asp + Glu) was 10 , while the total number of positively charged residues
(Arg + Lys) was 8. Multiple sequence alignment revealed the conserved GSH binding site (G-site) $\left(\mathrm{Lys}^{9}{ }^{9}, \mathrm{Cys}^{12}{ }^{12} \mathrm{Pro}^{13}\right.$, $\mathrm{Phe}^{14}, \mathrm{Gly}^{50}, \mathrm{Thr}^{53}$, and $\mathrm{Val}^{54}$ ), and catalytic residues (Cys ${ }^{12}$ and $\mathrm{Cys}^{15}$ ) were identified in the sequence (Figure 1). The blast search in the NCBI GenBank using the deduced amino acid sequence of PsGrx revealed that it had high sequence similarity to Trx-superfamily. The amino acid sequence of PsGrx shared 85.6\%, 74.4\%, 74.4\%, 72.2\%, and 50.0\% identity with P. haloplanktis TAC 125 Grx (YP_338909), P. agarivorans Grx (WP_004588615), P. haloplanktis Grx (WP_016708488), P. undina Grx (WP_010391834), and R. nanhaiensis Grx (WP_008217797), respectively. This indicated that PsGrx could be a novel Grx belonging to Trx-like superfamily.

3.2. Expression and Purification of the PsGrx. The recombinant vector pETgrx was constructed and transformed into E. coli BL21(DE3). rPsGrx was overexpressed by IPTG induction, and SDS-PAGE results showed a strong band approximately $15.0 \mathrm{kDa}$ was found compared to uninduced cells (Figure 2). The purification process resulted in a 5.81fold purification with $43.83 \%$ final recovery and $53.25 \mathrm{U} / \mathrm{mg}$ specific activity.

3.3. Biochemical Properties of rPsGrx. Effects of temperatures on the $\mathrm{rPs} G \mathrm{rx}$ activity were measured in temperature range of $0^{\circ} \mathrm{C}-60^{\circ} \mathrm{C}$ (Figure 3(a)). The optimal temperature for $\mathrm{rPs} \mathrm{Grx}$ activity was $30^{\circ} \mathrm{C}$. rPsGrx showed about $47.2 \%$ and $25.5 \%$ of its activity at $10^{\circ} \mathrm{C}$ and $0^{\circ} \mathrm{C}$, respectively. As for the thermal stability assay, $\mathrm{r} P s \mathrm{Grx}$ was evaluated by incubation at temperature $40^{\circ} \mathrm{C}$ and $50^{\circ} \mathrm{C}$ for $40 \mathrm{~min}$ (Figure 3(b)). rPsGrx showed $65.0 \%$ of its activity after incubation at $40^{\circ} \mathrm{C}$ for 20 min while lost almost all the activity after incubation at $50^{\circ} \mathrm{C}$ for $30 \mathrm{~min}$. Effect of $\mathrm{pH}$ on the Grx activity was studied using different $\mathrm{pH}$ buffers. As shown in Figure 3(c), rPsGrx showed activity in a broad $\mathrm{pH}$ range of 5.0-9.0. The maximal activity was observed at $\mathrm{pH}$ 8.0. But it was completely inactive in buffer $\mathrm{pH}$ 10.0.

Results regarding the effect of various compounds on the rPsGrx activity were shown in Table $1 . \mathrm{Mg}^{2+}, \mathrm{Zn}^{2+}, \mathrm{Cu}^{2+}$, $\mathrm{Ni}^{2+}$, and $\mathrm{Ca}^{2+}$ strongly inhibited the activity of rPsGrx by 93.0, 94.2, 85.0, 83.0, and 82.8\%, respectively. Addition of other metals, such as $\mathrm{K}^{+}, \mathrm{Fe}^{2+}, \mathrm{Fe}^{3+}$, and $\mathrm{Mn}^{2+}$, partially inhibited Grx activity. The presence of thiourea, DDT, Tween80, SDS, and $\mathrm{H}_{2} \mathrm{O}_{2}$ decreased the activity, and EDTA kept Grx activity with $79.7 \%$. It should be noted that $37.0 \%$ of the remaining activity was detected in the presence of high salt concentrations $(1 \mathrm{M} \mathrm{NaCl})$. Based on the LineweaverBurk plot, the $K_{m}$ and $V_{\max }$ values of rPsGrx using HED as substrate were $0.46 \mathrm{mM}$ and $14.3 \mathrm{nmol} / \mathrm{mL} / \mathrm{min}$, respectively.

\section{Discussion}

Based on the phylogeny, sequence, and domain structure, Grxs have been discovered and identified in various species. In the present study, a novel Grx gene from P. sp. AN178 was cloned and expressed in E. coli. The 270bp PsGrx gene with 89 amino acid $(9.8 \mathrm{kDa})$ was similar to some of the other Grx genes such as Chlorella virus $\mathrm{Grx}(9.0 \mathrm{kDa})$ [18], Trypanosoma 


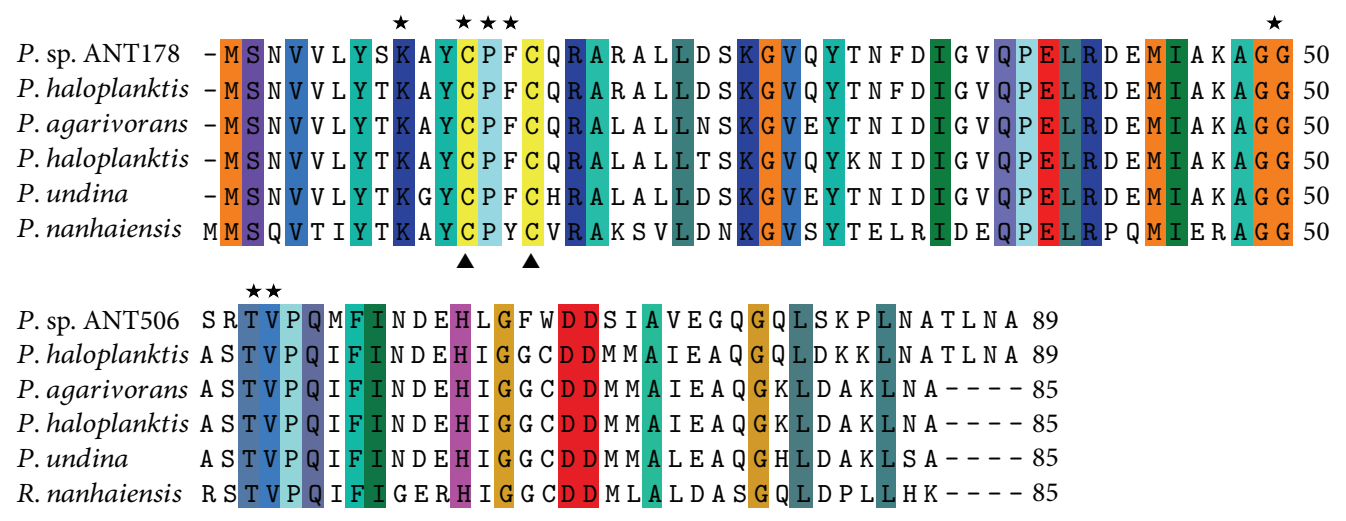

FIgURE 1: Alignment of amino acid sequences of PsGrx with the sequences of other Grxs. The displayed sequences are Pseudoalteromonas haloplanktis Grx (YP_338909), Pseudoalteromonas agarivorans Grx (WP_004588615), Pseudoalteromonas haloplanktis Grx (WP_016708488), Pseudoalteromonas undina Grx (WP_010391834), and Rheinheimera nanhaiensis Grx (WP_008217797). The shaded boxes in same color indicate identical residues. Symbols: closed triangles, cysteines (C) in the active site; pentagrams, residues involved in glutathione-binding site.

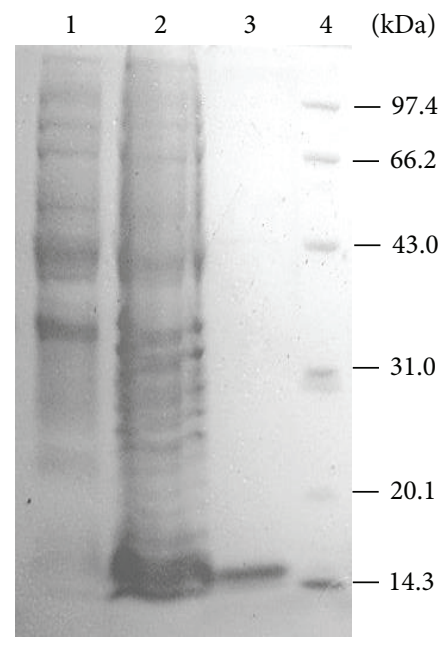

FIGURE 2: SDS-PAGE of the expression and purification of PsGrx in E. coli. lane 1: IPTG-induced E. coli BL21 $\left(\mathrm{Grx}^{-}\right)$; lane 2: a total cell lysate of IPTG-induced E. coli BL21 $\left(\mathrm{Grx}^{+}\right)$; lane 3: purified PsGrx; lane 4: molecular weight protein marker.

cruzi Grx (12.4 kDa) [19], Taiwanofungus camphorata Grx (11.0 kDa) [20], and Panax ginseng Grx (11.2 kDa) [21]. While larger molecular weight determination results to that of tomato SlGrxl (32.1 kDa) [22] and E. coli Grx2 (24.3 kDa) [23] have been reported, Grxs from different species may differ in their structures. Classical Grxs are $10 \mathrm{kDa}$ proteins with a CPYC active site (Grxl and Grx3 in E. coli and Grxl and Grx2 in yeast). A second group with a CGFS active site corresponds to yeast Grx3, Grx4, and Grx5 [24]. The third type, represented by E. coli Grx2, is structurally related to the GST [25]. In this study, Ps Grx contains the $\mathrm{N}$-terminal redox center $\mathrm{C}^{12}$ $\mathrm{PFC}^{15}$ sequence, which is typically CXXC motif present in Grx. Two cysteines in this motif were the source of reducing equivalents for substrate reduction. These residues formed reversible disulfide bond during catalysis and were shown to be the enzyme active site [1]. In addition, PsGrx also contains conserved C-terminal sequences involved in GSH binding, which exhibited highest homology to other Grxs. Multiple sequence alignment of the full-length $P_{s}$ Grx revealed that it shared the highest homologies with P. haloplanktis belonging to the TRX-like superfamily (Figure 1).

The optimum temperature for the rPsGrx was observed at $30^{\circ} \mathrm{C}$ (Figure $3(\mathrm{a})$ ). It was lower than the optimum temperature of Chlorella virus Grx $\left(37^{\circ} \mathrm{C}\right)$ [17]. The previous studies have shown that Grxs are ubiquitous small heat-stable proteins. Trypanosoma cruzi Grx retained approximately $50 \%$ of activity at $100^{\circ} \mathrm{C}$ for $8.5 \mathrm{~min}$ [19]; Brassica campestris Grx has no loss of activity at $95^{\circ} \mathrm{C}$ for $30 \mathrm{~min}$ [26], and Cryptococcus neoformans Grx was partially inactivated at $60^{\circ} \mathrm{C}$ or higher temperatures [27]. But $\mathrm{rPs}$ Grx activity still showed $65.0 \%$ of its activity after incubation at $40^{\circ} \mathrm{C}$ for 20 min (Figure 3(b)), which displayed low thermal stability. It was known that the common features of the cold active enzyme are high catalytic activities at low temperatures and low thermal stability. These results indicated that $\mathrm{r} P s \mathrm{Grx}$ was a cold active protein. As shown in Figure 3(c), optimum activity was observed at $\mathrm{pH}$ 8.0. This result was consistent with Grx from Brassica campestris ( $\mathrm{pH}$ 8.5) [26], Grx from Oryza sativa (pH 8.7) [28].

As shown in Table 1, 37.0\% of its optimum activity was detectable at $1.0 \mathrm{M} \mathrm{NaCl}$. This observation was found in other cold active enzymes from Antarctic sea-ice bacteria, such as $110.5,96.7$, and $81.4 \%$ of the GST, protease and lipase activity detected in the presence of $1.0 \mathrm{M}$ concentrations, respectively $[13,29,30]$. It was sensitive to SDS and thiourea, indicating that hydrogen bonds played an important role in maintaining Grx activity. $r P_{s} G r x$ was very sensitive to $\mathrm{H}_{2} \mathrm{O}_{2}$, and the similar result was described in the Grx from Oryza sativa [28], which could oxidize the reduced sulfhydryl groups. The $K_{m}$ values of $\mathrm{rPs}$ Grx $(0.46 \mathrm{mM})$ were much lower than that of Chlorella virus Grx (1.4-2.1 mM) [4], human Grx2 (1.68 mM) [23], and Cryptococcus neoformans Grx (1.03 mM) [27], indicating $r P s G r x$ had a higher affinity for the substrate HED. 


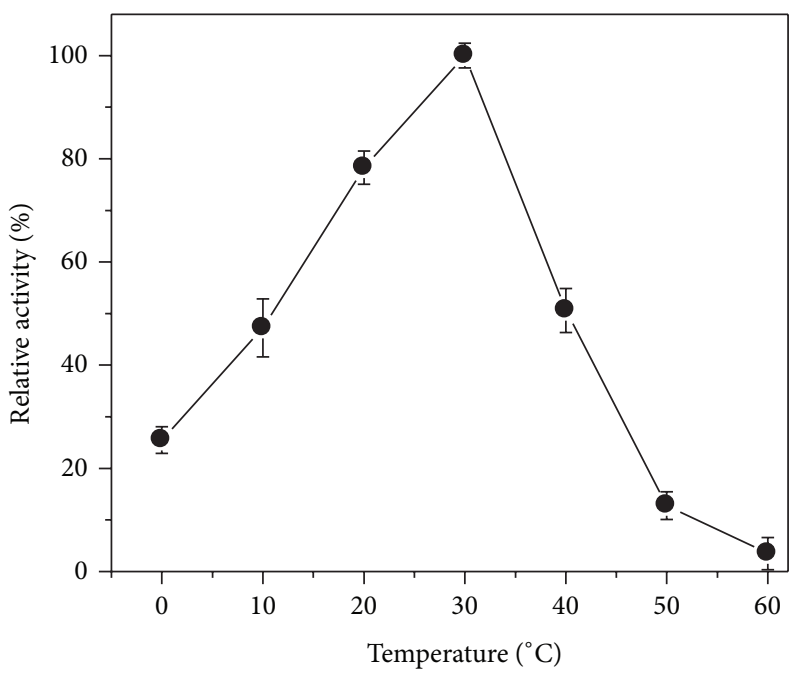

(a)

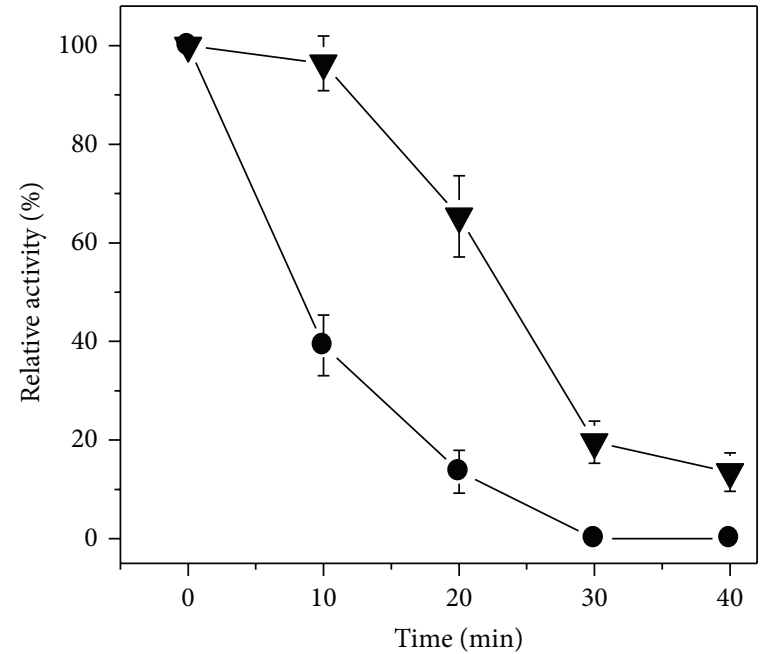

(b)

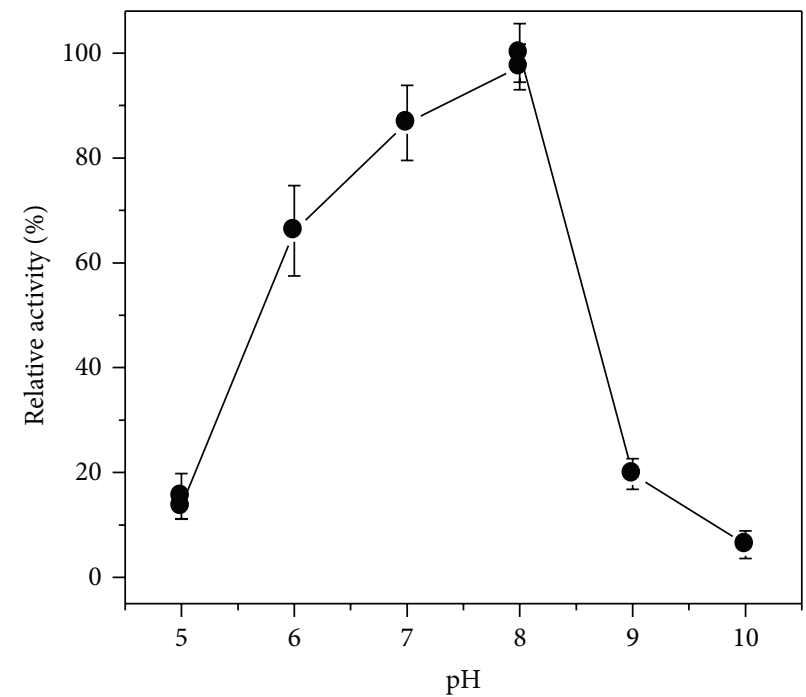

(c)

Figure 3: Biochemical properties of the rPsGrx. (a) Effect of temperatures on activity of the rPsGrx. (b) Effect of temperatures on the stability of the $\mathrm{rPs}$ Grx. The protein was incubated at $40^{\circ} \mathrm{C}$ closed triangles and $50^{\circ} \mathrm{C}$ closed circles for $10,20,30$, and 40 min, respectively and then directly put into an ice water bath and the residual activity was measured in the standard assay. (c). Effect of pH on activity of the rPsGrx.

In conclusion, compared with other Grxs, rPsGrx displayed specific catalytic properties and was a typical cold active protein with low thermal stability. Further studies are undergoing to understand the physiological function of Grx in Antarctic sea-ice bacteria under environmental stresses.

\section{Conflict of Interests}

The authors declare that there is no conflict of interests regarding the publication of this paper.

\section{Acknowledgments}

This study was supported by National Natural Science Foundation of China (31100037), the Natural Science Foundation of Shandong Province (ZR2011CM003 and ZR2009DQ023), and Natural Scientific Research Innovation Foundation in Harbin Institute of Technology (HIT-NSRIF201011).

\section{References}

[1] A. Holmgren, "Thioredoxin and glutaredoxin systems," The Journal of Biological Chemistry, vol. 264, no. 24, pp. 1396313966, 1989.

[2] T. C. Laurent, E. C. Moore, and P. Reichard, "Enzymatic synthesis of deoxyribonucleotides," The Journal of Biological Chemistry, vol. 239, pp. 3436-3444, 1964.

[3] E. Herrero, G. Bellí, and C. Casas, "Structural and functional diversity of glutaredoxins in yeast," Current Protein and Peptide Science, vol. 11, no. 8, pp. 659-668, 2010. 
[4] M. Zaffagnini, L. Michelet, V. Massot, P. Trost, and S. D. Lemaire, "Biochemical characterization of glutaredoxins from Chlamydomonas reinhardtii reveals the unique properties of a chloroplastic CGFS-type glutaredoxin," Journal of Biological Chemistry, vol. 283, no. 14, pp. 8868-8876, 2008.

[5] M. Luo, Y. Jiang, X. Ma et al., "Structural and biochemical characterization of yeast monothiol glutaredoxin Grx6," Journal of Molecular Biology, vol. 398, no. 4, pp. 614-622, 2010.

[6] E. Ströher and A. H. Millar, "The biological roles of glutaredoxins," Biochemical Journal, vol. 446, no. 3, pp. 333-348, 2012.

[7] N. Rouhier, J. Couturier, and J. Jacquot, "Genome-wide analysis of plant glutaredoxin systems," Journal of Experimental Botany, vol. 57, no. 8, pp. 1685-1696, 2006.

[8] E. Herrero and M. A. de La Torre-Ruiz, "Monothiol glutaredoxins: a common domain for multiple functions," Cellular and Molecular Life Sciences, vol. 64, no. 12, pp. 1518-1530, 2007.

[9] C. H. Lillig, C. Berndt, and A. Holmgren, "Glutaredoxin systems," Biochimica et Biophysica Acta, vol. 1780, no. 11, pp. 1304-1317, 2008.

[10] N. J. Russell, "Psychrophilic bacteria-molecular adaptations of membrane lipids," Comparative Biochemistry and Physiology, vol. 118, no. 3, pp. 489-493, 1997.

[11] Y. G. Gocheva, S. Tosi, E. T. Krumova et al., "Temperature downshift induces antioxidant response in fungi isolated from Antarctica," Extremophiles, vol. 13, no. 2, pp. 273-281, 2009.

[12] M. K. Chattopadhyay, G. Raghu, Y. V. R. K. Sharma, A. R. Biju, M. V. Rajasekharan, and S. Shivaji, "Increase in oxidative stress at low temperature in an antarctic bacterium," Current Microbiology, vol. 62, no. 2, pp. 544-546, 2011.

[13] R. Cotugno, M. Rosaria Ruocco, S. Marco et al., "Differential cold-adaptation among protein components of the thioredoxin system in the psychrophilic eubacterium Pseudoalteromonas haloplanktis TAC 125," Molecular BioSystems, vol. 5, no. 5, pp. 519-528, 2009.

[14] Y. G. Gocheva, E. T. Krumova, L. S. Slokoska, J. G. Miteva, S. V. Vassilev, and M. B. Angelova, "Cell response of Antarctic and temperate strains of Penicillium spp. to different growth temperature," Mycological Research, vol. 110, no. 11, pp. 13471354, 2006.

[15] Y. L. Shi, Q. F. Wang, Y. H. Hou et al., "Molecular cloning, expression and enzymatic characterization of glutathione Stransferase from Antarctic sea-ice bacteria Pseudoalteromonas sp. ANT506," Microbiological Research, vol. 169, pp. 179-184, 2014.

[16] Y. Meyer, B. B. Buchanan, F. Vignols, and J. P. Reichheld, "Thioredoxins and glutaredoxins: unifying elements in redox biology," Annual Review of Genetics, vol. 43, pp. 335-367, 2009.

[17] A. Holmgren and F. Aslund, "Glutaredoxin.," Methods in Enzymology, vol. 252, pp. 283-292, 1995.

[18] L. A. Fitzgerald, Y. Zhang, G. Lewis, and J. L. van Etten, "Characterization of a monothiol glutaredoxin encoded by Chlorella virus PBCV-1," Virus Genes, vol. 39, no. 3, pp. 418-426, 2009.

[19] V. E. Marquez, D. G. Arias, C. V. Piattoni, C. Robello, A. A. Iglesias, and S. A. Guerrero, "Cloning, expression, and characterization of a dithiol glutaredoxin from trypanosoma cruzi," Antioxidants \& Redox Signaling, vol. 12, no. 6, pp. 787-792, 2010.

[20] C. F. Ken, C. Y. Lin, Y. C. Jiang, L. Wen, and C. T. Lin, “Cloning, expression, and characterization of an enzyme possessing both glutaredoxin and dehydroascorbate reductase activity from Taiwanofungus camphorata," Journal of Agricultural and Food Chemistry, vol. 57, no. 21, pp. 10357-10362, 2009.
[21] Y.-J. Kim, J.-S. Shim, P. R. Krishna et al., "Isolation and characterization of a glutaredoxin gene from Panax ginseng C. A. Meyer," Plant Molecular Biology Reporter, vol. 26, no. 4, pp. 335-349, 2008.

[22] X. Yang and K. Ma, "Characterization of a thioredoxinthioredoxin reductase system from the hyperthermophilic bacterium Thermotoga maritima," Journal of Bacteriology, vol. 192, no. 5, pp. 1370-1376, 2010.

[23] V. N. Gladyshev, A. Liu, S. V. Novoselov et al., "Identification and characterization of a new mammalian glutaredoxin ( thioltransferase ), Grx2," Journal of Biological Chemistry, vol. 276, no. 32, pp. 30374-30380, 2001.

[24] M. T. Rodríguez-Manzaneque, J. Ros, E. Cabiscol, A. Sorribas, and E. Herrero, "Grx5 glutaredoxin plays a central role in protection against protein oxidative damage in Saccharomyces cerevisiae," Molecular and Cellular Biology, vol. 19, no. 12, pp. 8180-8190, 1999.

[25] B. Xia, A. Vlamis-Gardikas, A. Holmgren, P. E. Wright, and H. J. Dyson, "Solution structure of Escherichia coli glutaredoxin2 shows similarity to mammalian glutathione-S-transferases," Journal of Molecular Biology, vol. 310, no. 4, pp. 907-918, 2001.

[26] Y. Cho, E. Park, and C. Lim, "Thioltransferase (glutaredoxin) from Chinese cabbage: purification and properties," Journal of Biochemistry and Molecular Biology, vol. 31, no. 4, pp. 377-383, 1998.

[27] J. Sa, K. Kim, and C. Lim, "Purification and Characterization of Glutaredoxin from Cryptococcus neoformans," Molecules and Cells, vol. 7, no. 5, pp. 655-660, 1997.

[28] S. Sha, K. Minakuchi, N. Higaki et al., "Purification and characterization of glutaredoxin (thioltransferase) from rice (Oryza sativa L.)," Journal of Biochemistry, vol. 121, no. 5, pp. 842-848, 1997.

[29] Q. Wang, Y. Hou, Z. Xu, J. Miao, and G. Li, "Purification and properties of an extracellular cold-active protease from the psychrophilic bacterium Pseudoalteromonas sp. NJ276," Biochemical Engineering Journal, vol. 38, no. 3, pp. 362-368, 2008.

[30] Q. Wang, Y. Hou, Y. Ding, and P. Yan, "Purification and biochemical characterization of a cold-active lipase from Antarctic sea ice bacteria Pseudoalteromonas sp. NJ 70," Molecular Biology Reports, vol. 39, no. 9, pp. 9233-9238, 2012. 

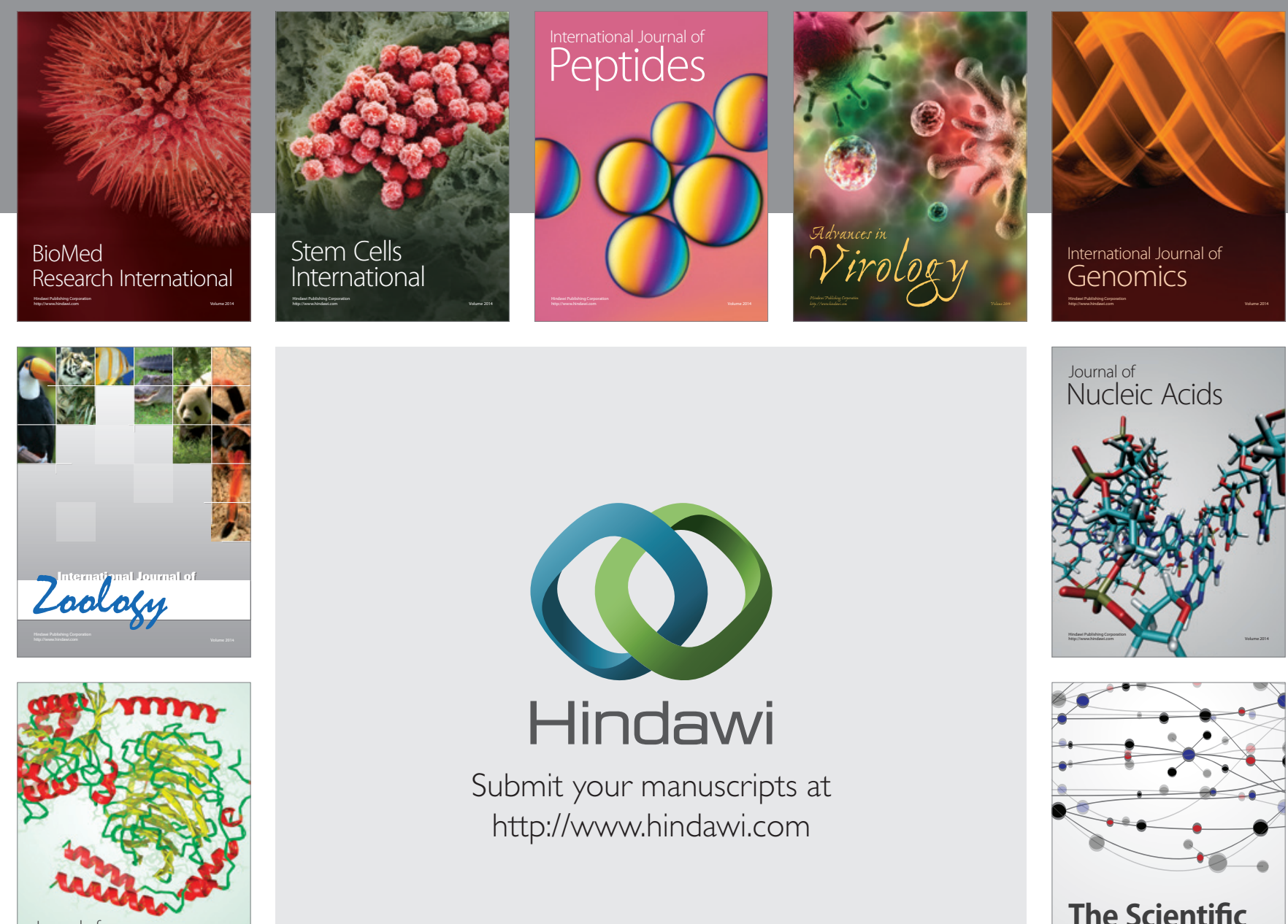

Submit your manuscripts at

http://www.hindawi.com

Journal of
Signal Transduction
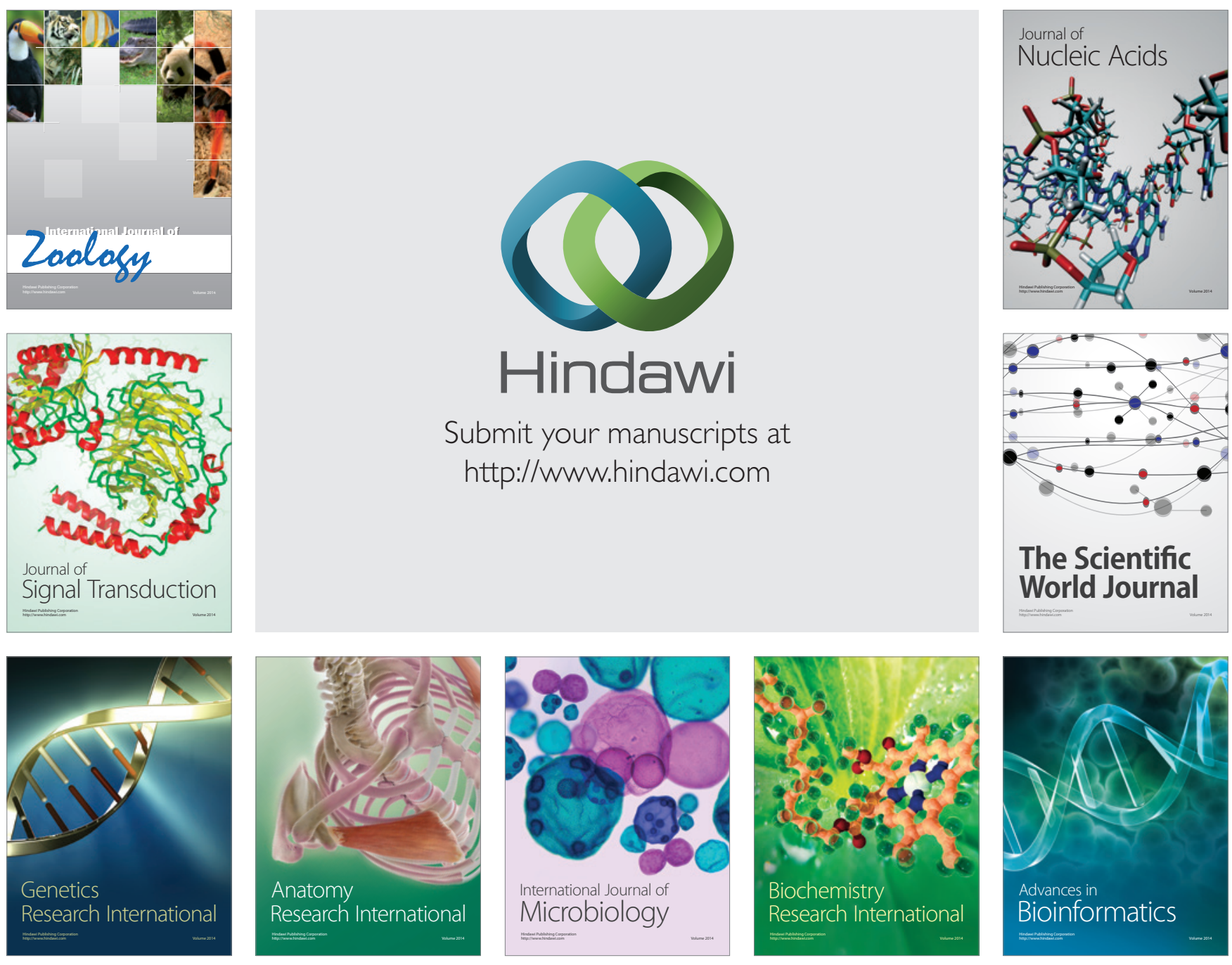

The Scientific World Journal
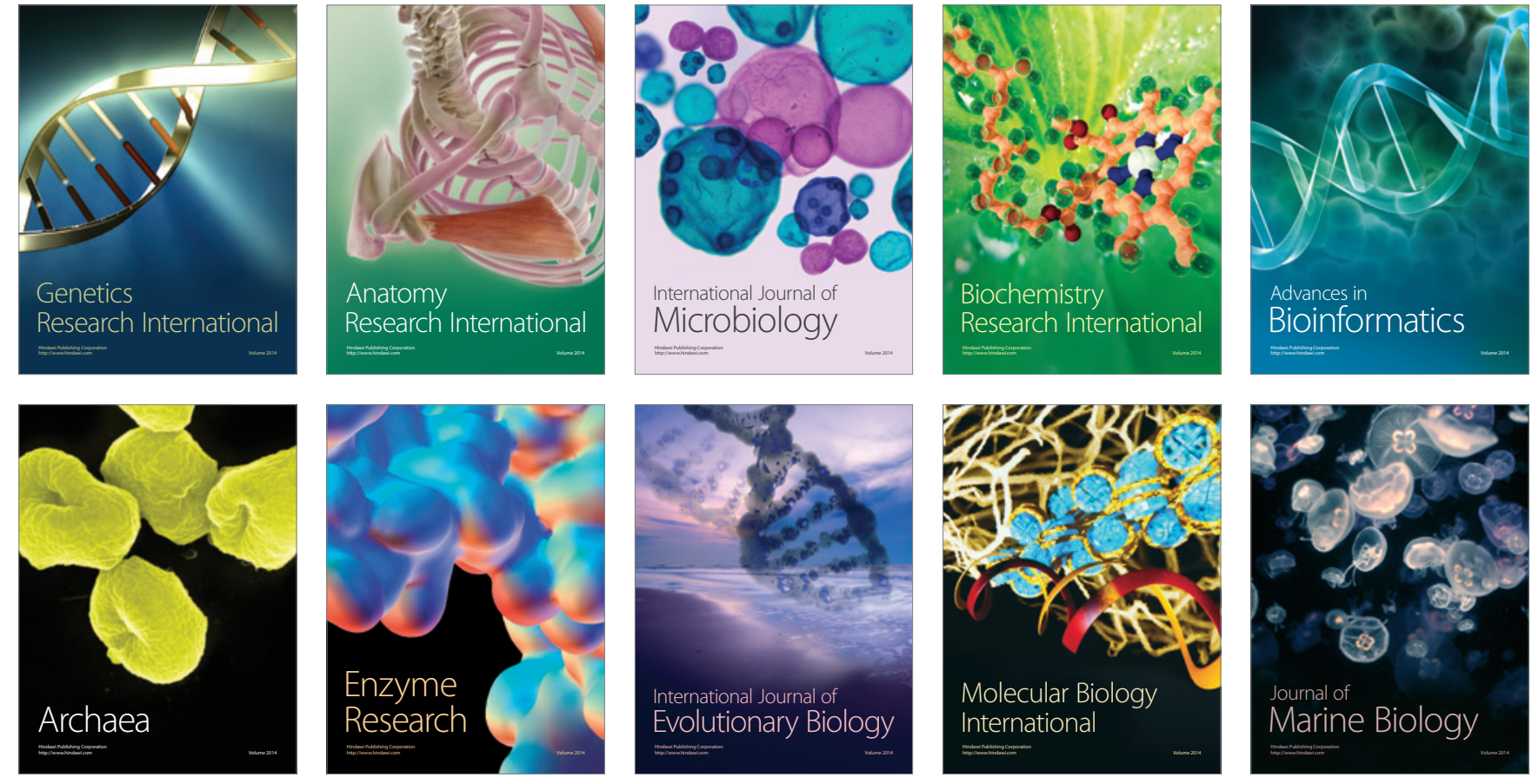